\title{
DESAFIOS NA GESTÃO ESCOLAR: NARRATIVAS DE DIRETORES E COORDENADORES PEDAGÓGICOS DE ESCOLAS PÚBLICAS
}

\author{
DESAFÍOS EN LA GESTIÓN ESCOLAR: NARRATIVAS DE DIRECTORES Y \\ COORDINADORES PEDAGÓGICOS DE ESCUELAS PÚBLICAS
}

\author{
CHALLENGES IN SCHOOL MANAGEMENT: NARRATIVES OF PUBLIC SCHOOL \\ PRINCIPALS AND PEDAGOGICAL COORDINATORS
}

Daiane Scopel BOFF ${ }^{1}$

Iriane ZULIANELO ${ }^{2}$

RESUMO: Este artigo discute a gestão escolar a partir das potencialidades e dificuldades mapeadas por diretores de escolas públicas de uma cidade do sul do país. Com aporte teórico em Meneses et al. (2001), Lück (2009) e Libâneo et al. (2012) descrevem-se as dificuldades evidenciadas pelos diretores em exercício na função, para posteriormente, investigar algumas formas de superação, considerando também o trabalho desenvolvido por coordenadoras pedagógicas que atuam nas mesmas escolas. O material empírico, produzido a partir de questionário e entrevista semiestruturada, mostra que a gestão escolar é atravessada por muitos desafios, que se acentuam com a falta de participação e engajamento familiar e na baixa motivação do corpo docente. Embora isso, alguns fatores promovem satisfação à equipe gestora, destacando-se o reconhecimento da comunidade escolar frente ao trabalho realizado e aos resultados alcançados, aspectos estes, que motivam o grupo a seguir em frente no trabalho de gestão.

PALAVRAS-CHAVE: Escola. Coordenação. Direção. Gestão.

RESUMEN: Este artículo analiza la gestión escolar en función de las potencialidades y dificultades asignadas por los ditrectores de escuelas públicas en una ciudad del sur. Con contribuición teórica en Meneses et al. (2001), Lück (2009) y Libaneo et al. (2012) describen las dificultades que evidencian los directores interinos en la función, para más adelante investigar algunas formas de superación, considerando también el trabajo desarrollado por las coordinadoras pedagógicas que trabajan en las mismas escuelas. El material empírico, producido a partir de un cuestionario y una entrevista semiestruturada, muestra que la gestión escolar está atravesada por muchos retos, que se acentúan por la falta de participación y compromiso familiar y la baja motivación del personal docente. Aunque esto, algunos factores promueven la satisfacción al equipo directivo, destacando el reconocimiento

\footnotetext{
${ }^{1}$ Instituto Federal de Educação, Ciência e Tecnologia do Rio Grande do Sul (IFRS), Caxias do Sul - RS Brasil. Professora de Matemática. Membro do GPMETA (IFRS) - Grupo de Pesquisa em Matemática, Ensino, Tecnologias e Aplicações e do GIPEDI (UNISINOS) - Grupo Interinstitucional de Pesquisa em Docências, Pedagogias e Diferenças. Doutora em Educação (UNISINOS). ORCID: https://orcid.org/0000-0002-2860-686X E-mail: daiane.boff@caxias.ifrs.edu.br

${ }^{2}$ Secretaria da Educação do Rio Grande do Sul (SEDUC RS), Flores da Cunha - RS - Brasil. Professora no Ensino Fundamental e Ensino Médio. Especialista em Docência em Educação Básica e Profissional (IFRS). ORCID: https://orcid.org/0000-0002-4666-0747 .E-mail: irianezulianelo@hotmail.com
} 
de la comunidad escolar en relación con el trabajo realizado y los resultados obtenidos, aspectos que motivan al grupo a avanzar en el trabajo de gestión.

PALABRAS CLAVE: Escuela. Coordinación. Dirección. Administración.

ABSTRACT: This article discusses school management based on the potential and difficulties mapped by public school principals in a city in the south of the country. With theoretical input in Meneses et al. (2001), Lück (2009) and Libâneo et al. (2012) it describes the difficulties evidenced by the principals in charge in the function, so then investigate some ways of overcoming, also considering the work developed by pedagogical coordinators who work in the same schools. The empirical material, produced from a questionnaire and semistructured interview, shows that school management is faced with many challenges, which are accentuated by the lack of participation and family engagement and the low motivation of the teaching staff. Despite this, some factors promote satisfaction to the management staff, highlighting the recognition of the school community regarding the work done and the results achieved, aspects that motivate the group to move forward in the management work.

KEYWORDS: School. Coordination. Direction. Management.

\section{Introdução}

A gestão escolar é tratada por muitos pesquisadores tais como Ferreira (2020), Lück (2009), Libâno, Oliveira e Toschi (2012), Meneses et al. (2011) e Lima e Santos (2007). Ao mesmo tempo, a construção de processos democráticos na gestão de escolas públicas está na agenda de muitas instituições. Nesse movimento, as escolas públicas de Educação Básica têm procurado qualificar seus processos de gestão de forma a atender, cada vez mais, as especificidades de suas funções.

Ao encontro disso, abordamos, neste texto, a gestão escolar a partir das potencialidades e dificuldades mapeadas por diretores ${ }^{3}$ de escolas públicas de um município do estado do Rio Grande do Sul e, ainda, a partir do olhar de coordenadoras pedagógicas que atuam no mesmo município. Embora nossa perspectiva inclua pais, estudantes, professores, direção, equipe pedagógica e demais funcionários no processo de gestão democrática de uma escola, este texto se dedica a apresentar a rotina e os tensionamentos que diretores e coordenadores pedagógicos enfrentam no exercício de suas funções. Com Lück (2009, p. 22) entendemos que os gestores escolares:

3 Embora tenhamos conhecimento dos estudos de gênero e das implicações do uso do termo diretores para referir-nos aos diretores e diretoras que participaram desta pesquisa, escolhemos não utilizar a flexão no termo para ter maior fluência no texto.

RPGE- Revista on line de Política e Gestão Educacional, Araraquara, v. 25, n. 3, p. 2163-2177, set./dez. 2021. e-ISSN: 1519-9029 
[...] são os profissionais responsáveis pela organização e orientação administrativa e pedagógica da escola, da qual resulta a formação da cultura e ambiente escolar, que devem ser mobilizadores e estimuladores do desenvolvimento, da construção do conhecimento e da aprendizagem orientada para a cidadania competente. [...] Sobretudo devem zelar pela constituição de uma cultura escolar proativa e empreendedora capaz de assumir com autonomia a resolução e o encaminhamento adequado de suas problemáticas cotidianas, utilizando-as como circunstâncias de desenvolvimento e aprendizagem profissional.

Além disso, Meneses et al. (2011) relatam que o diretor de uma escola exerce uma função complexa e que, além de se configurar como alguém de autoridade escolar, é também educador e administrador. Embora essa perspectiva coloque sobre o diretor uma ampla responsabilidade, pensamos que sua função é ainda mais complexa, visto que "a escola tem objetivos a atingir e compete ao diretor assumir a liderança para assegurar a consecução desses objetivos" (MENESES et al., 2011, p. 222). Segundo esses autores, o diretor precisa ter conhecimento dos diferentes setores da instituição, bem como sobre as políticas da escola, a fim de prezar pela sua execução, no alcance dos objetivos traçados pela comunidade escolar. Além disso, a avaliação dos resultados alcançados também precisa ser observada pelo diretor, já que é importante fazer uma análise a respeito do que deu certo, do que não deu certo ou do que poderia ter sido melhor durante o ano letivo.

De acordo com Lück (2009, p. 22), é responsabilidade dos diretores escolares "zelar pela realização dos objetivos educacionais, pelo bom desempenho de todos os participantes da comunidade escolar e atingimento dos padrões de qualidade definidos pelo sistema de ensino e leis nacionais, estaduais e municipais".

Na gestão escolar, a direção e a coordenação pedagógica têm funções de coordenar o trabalho coletivo, estar a serviço das pessoas e da organização, democratizar as decisões, dividir responsabilidades, assessorar os professores prestando apoio e suporte quando necessário, entre outras. Além disso, realizam:

[...] as atividades de coordenação e acompanhamento do trabalho de pessoas, envolvendo o cumprimento das atribuições de cada membro da equipe, a realização do trabalho em equipe, a manutenção do clima de trabalho, a avaliação de desempenho (LIBÂNEO et al., 2012, p. 475).

De forma mais específica, o trabalho da coordenação pedagógica está associado, principalmente, com a formação continuada e a assessoria dos professores (LIMA; SANTOS, 2007). Sua função também é incluir a comunidade escolar nas atividades da escola, por meio de debates e discussões, a fim de qualificar sempre mais o processo educativo, bem como, 
incentivar o grupo docente a desenvolver seus trabalhos da melhor maneira possível, procurando auxiliá-lo quando problemas aparecerem. Umemura e Rosa (2020, p. 90) afirmam que o trabalho do coordenador pedagógico também consiste na abertura e na sustentação de diálogos entre a comunidade escolar podendo, assim, criar estratégias de engajamento em torno de um projeto comum e gerar um espaço democrático no qual todos possam intervir na tomada de decisão e na solução de problemas.

Considerando isso, este texto tece uma análise que busca apresentar as principais dificuldades e potencialidades encontradas por profissionais que estão na função de direção escolar em instituições públicas de ensino para, na sequência, apresentar o trabalho de coordenadoras pedagógicas dessas instituições, investigando o que elas pensam sobre as dificuldades relatadas pelos diretores e como entendem que auxiliam nessas demandas.

\section{Caminhos metodológicos}

Esta pesquisa é de cunho qualitativo, pois se preocupa com o aprofundamento da compreensão de um grupo social, entendendo e analisando suas experiências (SILVEIRA; CÓRDOVA, 2009). A superfície de análise foi constituída por 14 escolas públicas de Educação Básica de um município do estado do Rio Grande do Sul, sendo 8 escolas da Rede Municipal de Ensino e 6 escolas da Rede Estadual. O total de escolas participantes da pesquisa corresponde a aproximadamente $94 \%$ das escolas públicas do município.

Das escolas analisadas, 12 ofertam somente o Ensino Fundamental e duas ofertam o Ensino Fundamental e o Ensino Médio. O material empírico ${ }^{4}$ foi produzido a partir de um questionário de questões abertas, aplicado a 14 diretores das escolas, e por meio de entrevista semiestruturada, realizada com duas coordenadoras pedagógicas que atuavam em algumas dessas escolas. Com o questionário, foi possível conhecer a rotina de trabalho dos diretores, bem como mapear as dificuldades e as potencialidades encontradas na função. Com as entrevistas, investigou-se o que as coordenadoras pedagógicas pensam sobre as dificuldades evidenciadas pelos diretores e de que forma elas auxiliam nas demandas da escola, especificamente, nas apontadas pelos diretores escolares.

Com o material produzido pelo questionário, por meio de análise de conteúdo (BARDIN, 2011), fizemos diferentes operações, que nos permitiram descrever, agrupar recorrências e analisar os sentidos que apareceram nas falas dos diretores em cada questão.

${ }^{4}$ Todos os participantes foram devidamente esclarecidos sobre a pesquisa e tiveram a opção de participar dela ou não. O Termo de Consentimento Livre e Esclarecido (TCLE) foi entregue e assinado em duas vias, ficando uma com o participante e outra com as pesquisadoras.

RPGE- Revista on line de Política e Gestão Educacional, Araraquara, v. 25, n. 3, p. 2163-2177, set./dez. 2021. e-ISSN: 1519-9029 
No escrutínio da materialidade, construímos seis categorias para apresentar as dificuldades descritas pelos diretores escolares, que denominamos: recursos humanos, recursos financeiros, corpo docente, família, estudantes e encargos da função. As categorias foram criadas considerando o direcionamento dados pelos diretores nas suas falas e evidenciam os impasses narrados na função de direção escolar. O quadro abaixo apresenta as dificuldades apontadas e suas recorrências:

Quadro 1 - Dificuldades encontradas na função de direção escolar

\begin{tabular}{|c|c|c|}
\hline Categorias & Dificuldades encontradas na gestão escolar & $\begin{array}{l}\text { Frequência } \\
\text { relativa }\end{array}$ \\
\hline Recursos humanos & Falta de funcionários e professores & $36 \%$ \\
\hline \multirow{2}{*}{ Recursos financeiros } & Falta de dinheiro que gera estrutura física precária & $7 \%$ \\
\hline & Excesso de burocracia com relação às verbas públicas & $21 \%$ \\
\hline \multirow{6}{*}{ Corpo docente } & Lidar com professores & $14 \%$ \\
\hline & $\begin{array}{l}\text { Unir e engajar o grupo docente, a fim de alcançar as metas } \\
\text { estabelecidas na proposta pedagógica }\end{array}$ & $7 \%$ \\
\hline & Auxiliar na motivação dos professores & $36 \%$ \\
\hline & Receber professores que não se sentem preparados & $7 \%$ \\
\hline & $\begin{array}{l}\text { Lidar com a falta de comprometimento e envolvimento de } \\
\text { alguns docentes }\end{array}$ & $7 \%$ \\
\hline & Lidar com a resistência a mudanças & $14 \%$ \\
\hline \multirow[b]{2}{*}{ Família } & Lidar com os pais & $14 \%$ \\
\hline & $\begin{array}{l}\text { Promover o engajamento, participação e a contribuição da } \\
\text { família na vida escolar de seus filhos }\end{array}$ & $43 \%$ \\
\hline \multirow[t]{2}{*}{ Estudantes } & $\begin{array}{l}\text { Entender a realidade dos estudantes e compreender o que } \\
\text { eles gostam, a fim de integrar os conteúdos para serem mais } \\
\text { significativos }\end{array}$ & $7 \%$ \\
\hline & $\begin{array}{l}\text { Lidar com a falta de interesse e indisciplina por parte dos } \\
\text { estudantes }\end{array}$ & $7 \%$ \\
\hline \multirow{5}{*}{ Encargos da função } & $\begin{array}{l}\text { Assumir compromissos e responsabilidades que, com } \\
\text { frequência, demandam tempo fora da escola }\end{array}$ & $14 \%$ \\
\hline & $\begin{array}{l}\text { Ter uma visão do todo, a fim de suprir com as necessidades } \\
\text { de todos os setores, para o bom funcionamento da escola }\end{array}$ & $7 \%$ \\
\hline & Lidar com as cobranças por parte da comunidade escolar & $7 \%$ \\
\hline & Trabalhar com a diversidade & $7 \%$ \\
\hline & $\begin{array}{l}\text { Expressar-se de forma clara para que todos entendam a } \\
\text { mesma coisa }\end{array}$ & $7 \%$ \\
\hline
\end{tabular}

Fonte: Elaborado pelas autoras

Após a produção do material empírico pelo questionário, ampliamos a discussão sobre as dificuldades e potencialidades mapeadas na função de direção escolar, a partir de entrevista semiestruturada com duas coordenadoras pedagógicas que atuavam em duas das escolas já 
participantes da pesquisa, o que permitiu investigar de forma mais ampla os desafios que a gestão escolar impõe.

Neste texto, considerando o material empírico produzido, exploramos as dificuldades mais recorrentes nas narrativas dos diretores escolares, a saber: promover o engajamento, participação e a contribuição da família na vida escolar de seus filhos e auxiliar na motivação dos professores ${ }^{5}$.

Na próxima seção, apresentamos uma análise sobre a dificuldade mais evidenciada nas falas dos diretores: a falta de participação e engajamento da família na vida escolar dos seus filhos. Além disso, descrevemos a rotina de trabalho das coordenadoras pedagógicas que atuam nas escolas, apresentando as atividades que desenvolvem e como elas auxiliam na gestão escolar.

\section{Participação e engajamento familiar: fator de destaque para a eficiência da gestão escolar?}

Na pesquisa realizada, a partir das falas dos diretores de escola, é possível ver que a falta de participação das famílias na vida da escola e na rotina escolar dos estudantes atua negativamente na gestão. Dentre os diretores entrevistados, aproximadamente $43 \%$ apontam esse fator como a principal dificuldade encontrada. Sousa e Sarmento (2010, p. 8) afirmam que:

[...] a escola não poderá desempenhar verdadeiramente o seu papel se não puder contar com o apoio da família. É esta quem melhor conhece as potencialidades, as características específicas de cada aluno, sendo, por isso, o ator mais bem colocado para subvencionar a escola e os professores de informações fundamentais para o desenvolvimento de projetos e estratégias mais adequadas, continuando os pais a ser os primeiros, permanentes e mais importantes professores das crianças.

De acordo com esses autores o envolvimento da família na escola permite que a criança se sinta mais motivada e se posicione de forma mais otimista e confiante em relação às suas aprendizagens, o que garante a potencialização do sucesso. Para seis dos 14 diretores participantes da pesquisa, existe, na escola em que desempenham sua função, uma difículdade muito grande em conscientizar as famílias dos estudantes de que para a escola atingir seus

${ }^{5}$ A falta de funcionários e professores também foi uma dificuldade bastante recorrente nas narrativas dos diretores das escolas públicas. Porém, optamos por não aprofundar esse impasse, já que em escolas públicas, a contratação de profissionais não depende da equipe gestora.

RPGE- Revista on line de Política e Gestão Educacional, Araraquara, v. 25, n. 3, p. 2163-2177, set./dez. 2021. e-ISSN: 1519-9029 
objetivos educacionais é necessário que os pais participem e acompanhem a vida escolar de seus filhos. As narrativas a seguir exemplificam isso:

Diretor 5: Para atingirmos resultados satisfatórios é preciso unir o grupo escolar como um todo e isso está interligado à participação também dos pais na comunidade escola; a maioria dos pais não participa da rotina escolar.

Diretor 13: A principal dificuldade, ou uma delas, é conscientizar a comunidade (familia) de que são parte fundamental para que aconteça uma educação efetiva e com qualidade.

Considerando que a temática da participação familiar foi recorrente nas falas dos diretores, buscamos, por meio de entrevista com coordenadoras pedagógicas, ampliar a análise feita a partir do trabalho que elas realizam, o que nos permitiu ver a rotina de trabalho dessas profissionais, as demandas que chegam até elas e ainda, como elas analisam essa dificuldade mapeada pelos diretores das escolas.

$\mathrm{Na}$ entrevista, perguntamos às coordenadoras, identificadas neste texto por $\mathrm{CP}_{\mathrm{M}}$ (Coordenadora pedagógica de escola municipal) e $\mathrm{CP}_{\mathrm{E}}$ (Coordenadora pedagógica de escola estadual) como são suas rotinas e quais as demandas que chegam até elas. As narrativas abaixo mostram que as demandas da coordenação pedagógica se encontram, principalmente, no que se refere ao suporte e ao apoio aos professores:

СРм: [...] o coordenador pedagógico é um suporte, alguém que está aí para apoiar e seguir a caminhada.

СРм: [...] o coordenador vai ajudar o professor, vai orientar como ele deve proceder nas situações.

Divieso (2017) afirma que a atribuição principal da coordenação pedagógica é ouvir e apoiar os professores. $\mathrm{O}$ apoio e o suporte aos professores também acontecem por meio da formação continuada que, segundo o autor, é "como uma forma de melhorar a qualidade do processo de ensino-aprendizagem" (DIVIESO, 2017, p. 24). Por meio dela, é possível "assegurar que estes professores possam experimentar novas situações e tenham a possibilidade de refletir sobre elas" (DIVIESO, 2017, p. 24). Assim, a coordenação pedagógica:

[...] assume a função de mediador[a] das práticas educativas no espaço escolar. Este profissional é por essência um formador de professores e, como tal, também precisa desenvolver habilidades e competências que o permita auxiliar os professores nesse processo permanente de reflexão sobre a prática, nas rotinas diárias, na proposição de intervenções, na organização de 
projetos de interesse da escola e nas necessidades dos alunos (ASSUNÇÃO; FALCÃO, 2015, p. 2)

As falas das coordenadoras pedagógicas evidenciam que o trabalho de coordenação está interligado com a organização do planejamento dos professores, na proposta de trabalho, na organização de reuniões pedagógicas, na organização de reuniões com pais e com a formação dos estudantes. Para Lück (2009) a gestão pedagógica é a dimensão mais importante da escola, já que está relacionada com o foco da instituição, "que é o de promover aprendizagem e formação do aluno" (2009, p. 102). A autora destaca que o trabalho da coordenação pedagógica também está ligado diretamente ao estudante, sendo sua responsabilidade promover:

[...] a atualidade dos processos pedagógicos, a contextualização de seus conteúdos em relação à realidade, os métodos de sua efetivação, a utilização de tecnologias, a dinâmica de sua realização, a sua integração em um currículo coeso [...] (LÜCK, 2009, p. 94).

$\mathrm{Na}$ entrevista realizada com as coordenadoras pedagógicas, verificamos também que o trabalho que elas desempenham está relacionado com a elaboração de documentos pedagógicos, importantes para registrar os planejamentos e as ações realizadas na escola. Ademais, o trabalho das coordenadoras também se mostra realizado na intermediação entre professor e aluno, professor e pais e entre alunos. A narrativa a seguir exemplifica essa dimensão do trabalho da coordenação pedagógica:

CPE: [...] a coordenação pedagógica tem que se preocupar com o Regimento da escola, com o Projeto Político Pedagógico da escola, que é onde se define toda a conduta pedagógica, o currículo, o planejamento, os planos de estudos, os planos de trabalho; tem que atender a demanda burocrática em torno disso que a Mantenedora exige, que é a produção dos documentos em torno de todas as questões pedagógicas. Depois, orientamos os professores, fazemos a intermediação da relação do professor com o aluno, do professor com os pais, dos alunos entre eles mesmos, pois todas as relações da vivência na escola têm que ser objeto de atenção do coordenador pedagógico, pois é ligado diretamente à aprendizagem.

Cruz (2018) afirma que as atribuições do coordenador pedagógico se relacionam com a elaboração coletiva do Projeto Político Pedagógico, com a formação continuada de professores, com a supervisão e a organização macro de ações pedagógicas, com a orientação para pais, estudantes e professores, entre outras atividades, tendo sempre em vista o zelo para com os resultados da aprendizagem dos estudantes.

RPGE- Revista on line de Política e Gestão Educacional, Araraquara, v. 25, n. 3, p. 2163-2177, set./dez. 2021. e-ISSN: 1519-9029 
Além disso, outra questão explorada nas entrevistas com as coordenadoras pedagógicas dizia respeito à dificuldade mais evidenciada pelos diretores das escolas públicas analisadas, no que tange à participação e ao engajamento das famílias. As narrativas das coordenadoras pedagógicas reforçam que esta dificuldade é bastante recorrente nas escolas e que a ausência das famílias está cada vez mais frequente, como mostra os excertos:

СРм: [...] é uma situação bem delicada que estamos enfrentando em todas as escolas [...] os coordenadores das escolas falam muito isso: [...] a família não consegue estar presente, acompanhando.

CРм: A grande maioria dos pais tem uma ocupação, um dia muito cheio, questões de trabalho, mil coisas, e parece que eles não estão conseguindo acompanhar o ritmo com que as crianças estão se desenvolvendo, crianças ou adolescentes. Então, na verdade, eles não sabem o que fazer, então, delegam para a escola [....].

Ao serem questionadas sobre a forma como auxiliam na questão da participação e engajamento familiar, as coordenadoras pedagógicas citaram ações diárias e contínuas, mas continuaram apontando-as como um desafio. $\mathrm{A} \mathrm{CP}_{\mathrm{M}}$ disse que para aumentar a participação dos pais, é desenvolvida uma ação chamada Escola de Pais, onde cada escola da Rede desenvolve atividades para que os pais possam conhecer melhor a escola e suas rotinas, tais como oficinas e palestras. Além disso, organizam o Guia da Família, um projeto idealizado e desenvolvido para as crianças da Educação Infantil de quatro e cinco anos, conforme relato a seguir:

CPм: [...] neste ano de 2020 construímos o Guia da Família para a Educação Infantil de quatro e cinco anos. [...] as crianças ganham um livro, colorido e interativo, onde o professor de sala de aula cria ações para trazer os pais para a escola. [...] começando lá na Educação Infantil, eu entendo que o resultado futuro será diferente. [...] os pais vão sentir o gostinho de estar na escola, de participar, vão ver os resultados e aí eles poderão dar continuidade.

A $\mathrm{CP}_{\mathrm{E}}$ explicita que várias ações podem ser feitas, como, por exemplo, o dia da família na escola, reuniões e formações para pais, eventos, reorganização do Projeto Político e Pedagógico (PPP) com a participação dos pais, entre outras atividades. Essas ações parecem dialogar com a ideia de que:

[...] a busca de alternativas para a participação no contexto escolar mediante decisões pensadas, organizadas e efetivadas, traz maiores chances de sucesso, mediante o proposto de aumentar índices de participação dos pais em reuniões (FERREIRA, 2020, p. 137). 
Embora isso, a autora também destaca a importância de a escola realizar as reuniões em horários que favoreçam os pais trabalhadores, além de disponibilizar horários para atendimentos, esclarecimentos e acolhimento das famílias na escola, fatores estes, importantes para a corresponsabilidade entre família e escola (FERREIRA, 2020).

A participação das famílias dos estudantes na escola pode também proporcionar à equipe escolar satisfação, já que o trabalho desses profissionais se torna facilitado, apoiado e reconhecido (SOUSA; SARMENTO, 2010). Esta pesquisa mostra também que para os diretores escolares há uma grande alegria em ver toda a comunidade escolar participando e envolvida na aprendizagem e no bem estar coletivo. Para grande parte dos diretores (42,85\%), o reconhecimento de pais, alunos e professores é o que os motivam a estar na função de direção, como mostram os excertos a seguir:

Diretor 10: Ser diretora dessa escola é extremamente gratificante. Desde o momento em que eu chego na escola até a saída dela, todos os dias. Os alunos sempre me procuram para ajudar [...] e, no final da manhã e da tarde, sempre me dão aquele beijo e um até amanhã. Essas demonstrações de reconhecimento são as partes boas, porque quem opta por nossa profissão, sabe que sempre buscamos o melhor para o nosso aluno.

Diretor 11: A melhor parte de estar diretor é o reconhecimento de nosso trabalho por parte da comunidade escolar.

Diretor 14: É muito bom ser diretora. São muitos desafios e conquistas, mas o retorno dos alunos é gratificante e emocionante. O reconhecimento das famílias com o cuidado que tenho pelos filhos deles. Enfim, quando realizamos o nosso trabalho com dedicação e valorização as coisas acontecem da melhor forma que se pode merecer.

As respostas dos diretores mostram que apesar de todos os obstáculos encontrados na função, o reconhecimento por parte da comunidade escolar torna-se a motivação fundamental. O carinho recebido pelos estudantes, os vínculos formados com a equipe escolar e a confiança depositada pelos pais fazem com que os diretores se sintam realizados. Temos compreendido que este é um ponto interessante a ser evidenciado.

Na próxima seção, buscamos desenvolver uma análise a respeito da falta de motivação docente, aspecto também evidenciado pelos diretores escolares como uma dificuldade potente na gestão escolar. Nesse ponto, as coordenadoras pedagógicas também contribuem na pesquisa, evidenciando suas perspectivas e destacando como auxiliam nessa demanda. 


\section{Motivação docente: fator que impulsiona a aprendizagem e a gestão escolar}

Trabalhar algumas questões com o corpo docente é uma tarefa complexa para os diretores escolares que participaram da pesquisa. Várias dificuldades envolvendo os professores foram relatadas pela gestão, sendo que a falta de motivação é a de maior recorrência. Para aproximadamente $36 \%$ dos diretores que participaram da pesquisa, há uma dificuldade em auxiliar na motivação dos professores, mantê-los unidos e comprometidos com a proposta da escola, a fim de alcançar os objetivos almejados. As falas dos diretores apontam que a desmotivação docente é um desafio para os profissionais que ocupam a função de direção, como vemos nos excertos:

Vice diretor $6^{6}$ : Os desafios da gestão escolar são diários. O maior é manter o grupo de professores unido e empenhado na realização da proposta pedagógica da escola.

Diretor 11: [...] o grande desafio é conseguir manter os professores motivados diante da atual situação salarial em que nos encontramos.

Professores que conseguem manter um nível satisfatório de autoestima e motivação podem influenciar mais positivamente no processo de ensino e de aprendizagem, pois "havendo professores motivados, teremos aulas motivadas, o que modificará o pensamento do aluno e o levará a descobrir uma série de motivos para aprender o conteúdo ministrado" (MENDES; GITAHY, 2006, p. 105).

Ao encontro disso, quando instigados a falar sobre a motivação docente, as coordenadoras pedagógicas entrevistadas afirmam que existe uma parcela significativa de professores desmotivados na profissão. Embora entendamos que as políticas públicas, como por exemplo, o Plano Nacional de Educação, bem como a Lei de Diretrizes e Bases da Educação, possuem em seu bojo uma valorização do docente, segundo as coordenadoras entrevistadas, a desmotivação docente acontece, em geral, por consequência de políticas que têm tratado a educação com depreciação, têm desvalorizado o trabalho do educador e têm pagado salários parcelados e escassos. Os excertos extraídos das entrevistas com as coordenadoras pedagógicas mostram isso:

$\mathbf{C P}_{\mathbf{E}}$ : [...] estamos sofrendo um processo de vários anos, um processo que é histórico, que desmotiva o professor. A questão salarial é o principal fator que desmotiva o professor. [...] a questão da carreira e a forma como as políticas públicas têm tratado a questão da educação [...] parece-me que é

${ }^{6} \mathrm{O}$ vice diretor participou da pesquisa na ausência do diretor. 
depreciação da escola, do ensino, da ciência e do conhecimento e, isso, acaba desmotivando o profissional.

СРм: [...] eu acredito que o que falta para os professores é um pouco mais de consideração e de respeito à profissão.

Muitos fatores parecem interferir na motivação dos professores. A pesquisa realizada por Mendes e Gitahy (2006) evidencia que as principais causas são com relação ao "descaso da família com a educação das crianças, a pouca valorização dada pelo governo à profíssão, indisciplina e desinteresse do aluno pelos conteúdos e alta carga horária a que o professor tem que se submeter para ter um ganho razoável [...]” (MENDES; GITAHY, 2006, p. 110).

Ao encontro dessa questão, quando questionadas sobre a forma como poderiam auxiliar na questão da motivação docente, as coordenadoras pedagógicas evidenciam que buscam conversar individualmente com os professores, principalmente ao perceber sinais de desmotivação, orientando-os, quando necessário, a procurar ajuda de especialistas. A preocupação com os professores fica evidente na fala de uma das coordenadoras:

$\mathbf{C P}_{\mathrm{E}}:$ [...] eu acho que a direção e a coordenação têm que se preocupar também com a motivação do professor. Com o entusiasmo, principalmente, proporcionar na escola um ambiente bom de trabalho, um ambiente favorável, com materiais, oferecendo possibilidades para que ele possa reconhecer o valor do seu trabalho.

Da mesma forma que compreendemos que a motivação docente pode contribuir para resultados mais positivos no processo de ensino e de aprendizagem, a motivação das pessoas que ocupam os cargos da gestão escolar também viabiliza melhores efeitos em relação aos seus trabalhos. Muitos diretores escolares que participaram da pesquisa sinalizaram alguns fatores que os motivam a desenvolver o trabalho de gestão:

Diretor 2: Estar na direção de uma escola é liderar pessoas e saborear resultados que eu também auxiliei, participei, conduzi.

Diretor 13: O lado bom do nosso trabalho é perceber nos alunos, todos os dias, que nosso empenho faz a diferença na vida de cada um deles. E que, com isso, ajudamos a formar cidadãos melhores, pessoas melhores.

O que este estudo mostra é que embora os diretores das escolas públicas entrevistadas apontem dificuldades no exercício de sua função, eles sentem-se satisfeitos ao verificar que os resultados de seus trabalhos são positivos. Isso mostra que perceber o crescimento dos estudantes perante as suas trajetórias escolares, parece garantir aos diretores que o trabalho da 
comunidade escolar está sendo mais eficaz e, esse fator, também faz com que esses profissionais se sintam mais motivados a permanecer na função.

\section{Considerações finais}

Esta pesquisa mostrou que estar na função de direção escolar é uma tarefa que exige responsabilidade, sensibilidade, comprometimento, força de vontade e conhecimento sobre os diferentes setores da escola: pedagógico, administrativo, financeiro e recursos humanos. Verificamos que, no exercício da função, os diretores das escolas públicas encontram muitas dificuldades, que podem ser minimizadas, com o auxílio das demais pessoas que fazem parte da comunidade escolar, especialmente, os coordenadores pedagógicos.

Dentre as dificuldades mais evidenciadas pelos diretores, a falta de participação e engajamento das famílias na vida escolar dos estudantes tem sido considerada um obstáculo a ser enfrentado pela escola, mesmo que os coordenadores pedagógicos e professores auxiliem nessa demanda por meio do planejamento de ações que possibilitem trazer os pais para mais perto da escola. Além disso, outro obstáculo bastante recorrente nas falas dos diretores escolares foi auxiliar na motivação dos professores, perante a desvalorização do trabalho docente e algumas vezes, perante a falta de consideração e engajamento de alguns professores para com a profissão.

Embora sejam muitas as dificuldades apontadas pelos diretores escolares na função que desempenham, esta pesquisa mostra também que existem fatores que promovem contentamento, como por exemplo: adquirir conhecimento de questões administrativas e pedagógicas, aprender com os desafios de cada dia, ter autonomia em determinadas situações, poder criar vínculos com toda a comunidade escolar, saborear resultados positivos e receber reconhecimento por parte da comunidade escolar, sendo esses dois últimos, os fatores mais evidenciados nas falas dos diretores. Esses e outros fatores impulsionam muitos diretores a seguir em frente com o compromisso pela educação, por meio da gestão escolar.

\section{REFERÊNCIAS}

ASSUNÇÃO, O. H. G.; FALCÃO, R. O. O coordenador pedagógico e a formação continuada de professores: uma pesquisa-ação no município de Fortaleza. In: REUNIÃO CIENTÍFICA DA ANPED, 37., 2015, Florianópolis. Anais [...] Florianópolis, SC: ANPED, 2015. Disponível em: https://anped.org.br/sites/default/files/trabalho-gt08-3706.pdf. Acesso em: 25 set. 2020. 
BARDIN, L. Análise de conteúdo. São Paulo, SP: Edições 70, 2011.

CRUZ, K. C. O papel do coordenador pedagógico na formação continuada de professores dos anos finais do ensino fundamental para uso das TDIC. Orientador: Rosemara Perpetua Lopes. 2018. Dissertação (Mestrado em Educação) - Universidade Federal de Goiás, Jataí, 2018. Disponível em:

https://repositorio.unesp.br/handle/11449/150775. Acesso em: 25 set. 2020.

DIVIESO, L. H. I. Formação em serviço de professores dos anos iniciais do ensino fundamental para utilização de tecnologias digitais no ensino da matemática. Orientador: Maria Raquel Miotto Morelatti. 2017. Dissertação (Mestrado em Educação) - Faculdade de Ciências e Tecnologia, Universidade Estadual Paulista, Presidente Prudente, 2017. Disponível em: https://repositorio.unesp.br/handle/11449/150775. Acesso em: 25 set. 2020.

FERREIRA, C. R. O modelo de gestão na ótica do diretor de escola do programa ensino integral. Orientador: Sebastião de Souza Lemes. 2020. Tese (Doutorado em Educação) Faculdade de Ciências e Letras, Universidade Estadual Paulista, Araraquara, 2020. Disponível em: https://repositorio.unesp.br/handle/11449/192031. Acesso em: 25 set. 2020.

LIBÂNO, J. C.; OLIVEIRA, J. F.; TOSCHI, M. S. Educação escolar: políticas, estrutura e organização. São Paulo, SC: Cortez, 2012. 543 p.

LIMA, P. G.; SANTOS, S. M. Coordenador pedagógico na educação básica: desafios e perspectivas. Educere Et Educare, Cascavel, v. 2, n. 4, p. 77-90, 2007. Disponível em: http://e-revista.unioeste.br/index.php/educereeteducare/article/view/1656/1343. Acesso em: 25 set. 2020 .

LÜCK, H. Dimensões de gestão escolar e suas competências. Curitiba, PR: Positivo, 2009. Disponível em:

https://edisciplinas.usp.br/pluginfile.php/2190198/mod_resource/content/1/dimensoes_livro.p df. Acesso em: 25 set. 2020.

MENDES, A. A.; GITAHY, R. R. C. Fatores que influem na motivação de professores da rede estadual de ensino, no exercício do magistério na cidade de Maringá - PR. Revista Cesumar - Ciências Humanas e Sociais Aplicadas, Maringá, v. 11, n. 2, p. 97-112, 2006. Disponível em:

https://periodicos.unicesumar.edu.br/index.php/revcesumar/article/view/298/142. Acesso em: 25 set. 2020.

MENESES, J. G. C. et al. Educação básica: políticas, legislação e gestão. Leituras. São Paulo, SP: Cengage Learning, 2011. 285 p.

SILVEIRA, D. T.; CÓRDOVA, F. P. A pesquisa científica. In: GERHARDT, T. E.; SILVEIRA, D. T. (Org.). Métodos de pesquisa. Porto Alegre, RS: Editora da UFRGS, 2009. p. 31-42. Disponível em: http://www.ufrgs.br/cursopgdr/downloadsSerie/derad005.pdf. Acesso em: 25 set. 2020.

SOUSA, M. M.; SARMENTO, T. Escola - Família - Comunidade: uma relação para o sucesso educativo. Gestão e Desenvolvimento, Viseu, n. 17-18, p. 141-156, 2010. Disponível em: https://repositorio.ucp.pt/handle/10400.14/9117. Acesso em: 25 set. 2020.

RPGE- Revista on line de Política e Gestão Educacional, Araraquara, v. 25, n. 3, p. 2163-2177, set./dez. 2021. e-ISSN: 1519-9029 
UMEMURA, V. M. V.; ROSA, S. S. Desafios dos coordenadores pedagógicos de São Caetano do Sul, ABC Paulista: um estudo baseado na pesquisa-ação colaborativa. Interações, Campo Grande, v. 21, n. 1, p. 81-92, 2020. Disponível em:

https://www.scielo.br/scielo.php?pid=S1518-70122020000100081\&script=sci_arttext. Acesso em: 25 set. 2020 .

\section{Como referenciar este artigo}

BOFF, D. S.; ZULIANELO, I. Desafios na gestão escolar: narrativas de diretores e coordenadores pedagógicos de escolas públicas. Revista on line de Política e Gestão Educacional, Araraquara, v. 25, n. 3, p. 2163-2177, set./dez. 2021. e-ISSN:1519-9029. DOI: https://doi.org/10.22633/rpge.v25i3.14249

Submetido em: 29/09/2021

Revisões requeridas em: 28/10/2021

Aprovado em: 15/11/2021

Publicado em: 08/12/2021 